\title{
LAS HOJAS DE LAUREL DEL SOLUTRENSE SUPERIOR DE LA CUEVA DE AMBROSIO: ANÁLISIS MORFOLÓLOGICO, TIPOMÉTRICO Y TECNOLÓGICO
}

\author{
Laurel leaves of the Upper Solutrean at Ambrosio's Cave: \\ morphologic, typometrical and technological analysis
}

Francisco Javier Muñoz Ibáñez*

Recibido el 19 de abril de 2008. Aceptado el 10 de mayo de 2008

Resumen. En este trabajo se aborda el estudio de las hojas de laurel, que se encuadran en el Solutrense Superior de la Cueva de Ambrosio. Este tipo de proyectiles se caracterizan a partir de parámetros morfológicos, tipométricos y tecnológicos. Se propone un modelo teórico sobre los procesos de fabricación y su repercusión en el registro arqueológico.

Palabras clave: Hoja de laurel. Tecnología lítica. Reducción bifacial. Solutrense. Sureste español.

Abstract. This paper deals with the study of the laurel leaves, coming from the Upper Solutrean at Cueva de Ambrosio. This type of projectile points are characterized from morphological, typometrical and technological parameters. A theoretical model is proposed to explain the manufacturing processes and their effect on the archaeological record.

Key Words: Laurel leave. Lithic technology. Bifacial work. Solutrean. Spanish southeastern.

\section{INTRODUCCIÓN}

En este artículo se aborda una primera aproximación al estudio tecnológico de los foliáceos bifaciales del Solutrense extracantábrico. Para este trabajo se han analizado los materiales del Solutrense superior de la Cueva de Ambrosio procedentes de las campañas de excavación realizadas por el prof. Eduardo Ripoll y por el Dr. Sergio Ripoll.

Este yacimiento es suficientemente conocido en la bibliografía especializada y ha sido objeto de numerosas pu-
Hay dos maneras de difundir la luz... ser la lámpara que la emite, o el espejo que la refleja. Lin Yutang (1895-1976).

Gracias al Profesor Eduardo Ripoll por su incansable vocación de ser "lámpara" para los que tuvimos la suerte de conocerle.

blicaciones (Ripoll, E. 1960-61, 1962; Ripoll, S. 1986, 1988; Ripoll y Cacho, 1990; Ripoll et al., 1997; Muñoz, 2000; ...). Se encuentra situado en el extremo noroccidental de la provincia de Almería, en el municipio de Vélez Blanco, dentro de la comarca de "Los Vélez", donde aparecen los relieves calizos más desarrollados de toda la región. Esta zona montañosa es una vía de comunicación natural que une la costa mediterránea con el interior de Andalucía. Además, está ubicado en la cabecera del valle que forma el Arroyo del Moral, lo que a priori dota a este hábitat de gran interés para activi-

(*) Laboratorio de Estudios Paleolíticos. Dpto. de Prehistoria y Arqueologia. UNED. C/ Senda del Rey, 7. 28040-Madrid. fjmunoz@geo.uned.es 
dades cinegéticas. La Cueva de Ambrosio es realmente un gran abrigo triangular abierto en un farallón de casi $100 \mathrm{~m}$. de altura, de $39 \mathrm{~m}$ de ancho, $19 \mathrm{~m}$ de altura y penetra $17 \mathrm{~m}$. hacia el interior desde el borde de la visera. Está orientado hacia el S-SO, a una altura de 1.060 m.s.n.m. y a 15 m sobre el fondo del arroyo.

La excavación de los niveles solutrenses fue realizada a finales de la década de los 50 y principio de los 60 por E. Ripoll (1960-61 y 1962) y a partir de la década de los 80 por S. Ripoll (1988); continuando los trabajos en la actualidad. La secuencia estratigráfica de este periodo presenta hasta el momento tres niveles de ocupación que se corresponden con un Solutrense Medio (Nivel VI-16.590 1 1.400BP GIF7277), un Solutrense Superior (Nivel IV-16620 $\pm 280 B P$ GIF 7275) y un Solutrense Superior Evolucionado (Nivel II-

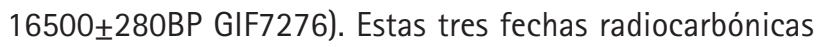
convencionales eran las únicas existentes para los niveles solutrenses. En la actualidad, contamos con nuevas dataciones calibradas para el Nivel IV y II que retrotraen en la escala cronoestratigráfica la posición de ambos estratos y que serán publicadas próximamente.

En la secuencia del Paleolítico superior de la península Ibérica, el Solutrense es uno de los periodos mejor conocidos desde el punto de vista cronológico, estratigráfico, climático, industrial y artístico. No obstante, aquellos elementos más característicos de esta cultura y que marcan un cambio fundamental y radical con respecto a momentos anteriores, las puntas líticas de proyectil, no cuentan con muchos trabajos especificos. El denominado Solutrense extracantábrico (Ripoll, 1988; Muñoz, 2000), en contraposición al Solutrense "clásico" de la cornisa cantábrica, Francia y Cataluña es muy homogéneo y cada fase está definida por unos componentes industriales muy marcados. El fenómeno solutrense en toda esta zona (Valencia, Murcia y Andalucia) se puede dividir en cuatro etapas básicas que articulan toda la secuencia (Muñoz, 2000).

Una primera fase, la Etapa de Formación, se correspondería con el Solutrense inferior. Únicamente hay dos yacimientos que contengan industrias que puedan ser adscritas con seguridad a este periodo: la Cova del Parpalló (Gandía) y de Les Mallaetes (Barig), ambos en la comarca valenciana de La Safor. En esta fase se asientan las bases tecnológicas que darán lugar a la posterior evolución de las puntas solutrenses. Aparece por primera vez el retoque plano en proyectiles unifaciales: punta de cara plana. Estas piezas se realizan sobre soportes laminares con retoques planos y cubrientes sobre el anverso y el extremo distal está apuntado. Tienen una morfología foliácea y gran simetría. Las más antiguas están hechas sobre hojas y lascas de un grosor mayor y mantienen la simetría solo cuando los retoques cubren casi todo el anverso. Paulatinamente, se escogen soportes más delgados, tienen contornos más regularizados y retoques en el reverso, fundamentalmente para adelgazar la zona bulbar y configurar la punta, con una fuerte tendencia a transformarse en piezas bifaciales. También aparecen los primeros ejemplos de talla bifacial: hoja de laurel.

Una segunda fase, la Etapa de Expansión, se identifica con el Solutrense medio. Se constata una ampliación de este tecnocomplejo a la provincia de Alicante y al este de Andalucía, Ilegando hasta la costa malagueña. El utillaje solutrense viene marcado por la consolidación de la talla bifacial, con el predominio de las hojas de laurel, realizadas mediante retoque plano, invasor y bifacial con el extremo distal apuntado y el proximal redondeado o también apuntado, sobre las puntas de cara plana que, no obstante, todavía mantienen un peso relativamente importante. Al final de esta etapa se observa una tendencia a la pedunculación en las hojas de laurel, cuyas morfologías adoptan una tipología de transición entre las hojas de laurel del subtipo "H" (Smith, 1966) y las puntas de aletas y pedúnculo. Por primera vez se detecta en el registro arqueológico las piezas solutrenses bifaciales.

La siguiente fase, la Etapa de Madurez, abarca el Solutrense superior. Ahora el Solutrense se extiende a otras zonas, unificando culturalmente un territorio bastante extenso. Así, aparecen nuevos yacimientos en Castellón, en el interior de Andalucía (Jaén), y sobre todo en la provincia de Cádiz. En el utillaje característico solutrense están todavía presentes las puntas de cara plana. Aunque su número es cada vez menor, a medida que nos alejamos de la región valenciana se hacen más frecuentes en el registro arqueológico. Las hojas de laurel, que mantienen su importancia en el total del utillaje de retoque plano, son cada vez más pequeñas, delgadas, y en ocasiones de bordes rectilíneos. En los proyectiles solutrenses se asienta la idea de la pedunculación, ensayada tímidamente al final de la etapa anterior. Así, las puntas de aletas y pedúnculo se convierten en los útiles distintivos de este periodo, después de los primeros esbozos realizados al final del Solutrense medio. El último tipo de proyectil representativo de este momento es la punta de muesca de tipo mediterráneo, que cada vez tendrá más peso específico en el total de las puntas de proyectil. Su reaparición en este momento, junto con el aumento del utiIlaje sobre hojita, sobre todo hojitas de dorso, testimonia una vuelta de las influencias gravetienses que se mantendrán cada vez con más fuerza.

La última fase, la etapa de Disgregación, es el Solutrense superior evolucionado. Durante este periodo los yacimientos ocupan las mismas zonas geográficas que en el anterior. El elemento característico y unificador del Solutrense, el retoque plano e invasor, va perdiendo su preeminencia en favor del retoque abrupto. Este fenómeno es más acusado en la zona oriental. Las hojas de laurel continúan estando presentes en casi todos los yacimientos, aunque su número disminuye considerablemente. Las puntas de aletas y pedúnculo casi desaparecen por completo de los yaci- 
mientos valencianos, mientras que en Murcia y Andalucia son todavía importantes. El útil más característico de toda esta etapa es la punta de muesca de tipo mediterráneo, superando en número a cualquier otro proyectil del grupo solutrense. Asimismo, el utillaje sobre hojita presenta un avance muy significativo con respecto a la etapa anterior.

\section{LA MUESTRA DE ESTUDIO}

El Solutrense representa el punto culminante en la evolución de la fabricación del instrumental lítico cinegético paleolítico y probablemente ninguna otra cultura del Paleolítico superior presente un porcentaje tan alto de útiles de sustrato. Una de las características comunes a todas las regiones donde aparece el Solutrense es la existencia de puntas de proyectil con morfologías foliáceas. Tradicionalmente, se ha considerado como un elemento diagnóstico el retoque plano e invasor con levantamientos estrechos y subparalelos para la fabricación de las mismas, realizados con percutor blando y/o por presión. Si bien es cierto que el retoque plano e invasor fue utilizado de forma esporádica en etapas anteriores, ahora su uso es sistemático en este tipo de utillaje.

En la elección de esta muestra de estudio han pesado criterios tanto de oportunidad, dado el carácter de esta publicación, como de representatividad. La secuencia evolutiva del Solutrense de esta región se articula fundamentalmente a partir de dos yacimientos de referencia (La Cueva de Ambrosio y La Cova del Parpalló), que presentan estratigrafías bien definidas y abarcan el lapso temporal donde aparecen estos proyectiles. La abundancia de hojas de laurel, en sus diferentes etapas de fabricación, convierte a estas dos estaciones en las únicas con series líticas especialmente significativas para hacer un estudio de esta naturaleza. En el resto, la extrapolación que se podría hacer de los datos de sus exiguas series líticas de este tipo de puntas de proyectil no sería suficientemente representativa de las mismas.

Se han estudiado un total de 186 piezas identificadas como hojas de laurel, procedentes del Solutrense superior de la Cueva de Ambrosio, que realmente responden a diferentes estados de transformación de la cadena operativa de fabricación. Esta colección ha sido clasificada en tres categorias básicas:

Hoja de laurel (HL): son proyectiles totalmente acabados que presentan un retoque plano invasor y bifacial, representan el 69,89\% del total (130 piezas), (figs. 11 y 12).

Hoja de laurel no acabada (HL.na): son proyectiles casi terminados con un retoque plano e invasor que en la mayoría de los casos es bifacial. No se pueden considerar hojas de laurel terminadas bien porque el adelgazamiento bifacial es insuficiente, presentan fracturas de fabricación y/o falta configurar la punta o adelgazar la base. Representan el 16,13\% del total (30 piezas), (fig. 10).
Pieza solutrense bifacial (PSB): son esbozos de hojas de laurel cuyo proceso de fabricación se encuentra en una fase inicial. Están realizadas sobre lascas y hojas espesas que presentan un retoque más o menos plano, generalmente por percusión directa con percutor duro y blando, que en muchos casos no llega a ser invasor. Representan el 13,98\% del total (26 piezas), (fig. 9).

\section{MATERIA PRIMA}

Todos los proyectiles están realizados en las diferentes variedades de sílex detectados en el área de captación del yacimiento. La mayoría de los afloramientos se sitúan en el eje de los ríos Alcaide y Caramel, siendo relativamente abundantes y de fácil acceso. Los estudios realizados sobre las fuentes de materias primas del la Cueva de Ambrosio (Ripoll, 1988) permiten establecer a nivel macroscópico la existencia de sílex de tipo criptocristalino y sílex de tipo jaspeado. El primer grupo responde bastante bien a la talla laminar aunque es más difícil de trabajar debido a su dureza. No obstante, esto le confiere a la pieza una gran resistencia. Presenta diferentes variedades, que atendiendo a su color puede ser gris, beige o blanco. El segundo grupo es el más abundante y característico del yacimiento, de grano muy fino y de excepcional calidad para la talla. Se corresponde con el sílex de color melado, negro y rojo. Aunque en realidad, la coloración de estos dos últimos es producto de una alteración de tipo térmico, que hace que los óxidos férricos se depositen en exterior de las piezas. Debido a que la mayoría de los restos líticos se encuentran en el interior de las estructuras de combustión es difícil saber si este calentamiento es intencionado y responde a una fase de la cadena operativa de talla o no.

En los proyectiles bifaciales analizados el 65,05\% están fabricados sobre sílex criptocristalino y el 34,95\% sobre sílex jaspeado, (fig. 1). Esta diferencia aumenta considerablemente en las PSB $(80,77 \%$ y $19,23 \%$, respectivamente), mientras las otras dos categorias mantienen valores cercanos al total del conjunto: $\mathrm{HL}(61,54 \%$ y $38,46 \%)$ y $\mathrm{HL}$.na $(66,67 \%$ y $33,33 \%)$. Dentro de los diferentes subtipos el más utilizado es el gris $(33,87 \%)$, seguido del melado $(29,57 \%)$, el beige $(19,35 \%)$ y el blanco $(12,37 \%)$. El resto tienen escasa repercusión en el total de la muestra, no superando el $4 \%$ (fig. 1). Tanto las HL como las HL.na presentan porcentajes muy parecidos: gris $35,38 \%$ y $33,33 \%$, melado $32,31 \%$ y $30,00 \%$, beige $19,23 \%$ y $16,67 \%$, respectivamente. Asimismo, hay un único ejemplar de $\mathrm{HL}$ realizado en sílex criptocristalino oolítico de color verdoso de muy mala calidad y escasa dureza. En las PSB el sílex blanco es mayoritario $(30,77 \%)$, frente al gris $(26,92 \%)$, beige $(23,8 \%)$ y melado $(15,38 \%)$. Si comparamos estos datos con los obtenidos para las puntas ligeras de proyectil del Solutrense superior de este yacimiento (Muñoz, 2000), observamos como en las 


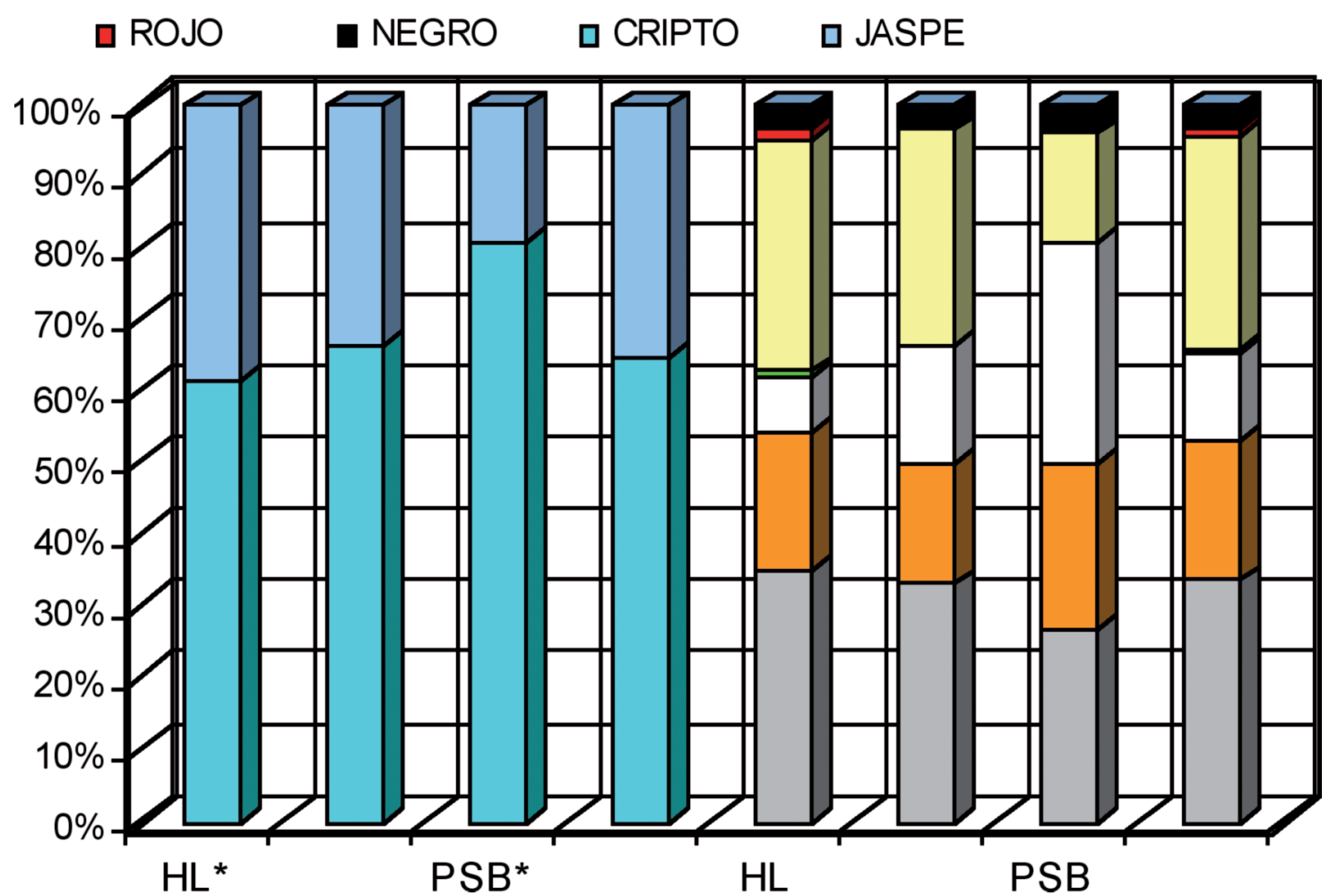

A Figura 1. Materias primas empleadas: tipos* y subtipos.

puntas de aletas y pedúnculo (PAP) no hay una búsqueda preferencial de un tipo determinado de materia prima $(52,39 \%$ criptocristalino y $47,61 \%$ jaspeado), mientas que en las puntas de muesca de retoque abrupto (PM) si hay un mayor uso del primero $(72,45 \%)$ frente al segundo tipo $(27,55 \%)$. En las PAP el sílex más usado es el melado, mientras que en las PM es el gris.

Las alteraciones que se han observado en los diferentes tipos de materia prima tienen escasa incidencia en el total de la muestra. Como alteraciones inherentes a la propia materia prima se han individualizado dos: impurezas y fisuras. El $35,48 \%$ presenta algún tipo de impureza, este valor es similar al de las PAP y ligeramente inferior al de las PM, (Muñoz, 2000). En cuanto a las fisuras, en tan solo 8 ejemplares (7 HL y $1 \mathrm{HLna}$ ) se constata este tipo de alteración, lo que supone un 4,30\%. Como alteraciones relacionadas con el calentamiento de las rocas silíceas se han identificado piezas desilificadas $(26,88 \%)$, cuarteadas $(0,54 \%)$ y craqueladas $(1,08 \%)$. Como en el conjunto de los materiales líticos de este yacimiento, la desilificación es la alteración más común, aunque en el caso de los foliáceos bifaciales este porcentaje es sensiblemente superior al que tienen las PAP $(7,14 \%)$ y las PM (11,22\%), (Muñoz, 2000).

El examen de las materias primas sobre las que están realizadas los foliáceos bifaciales revela que hay un predominio de sílex criptocristalino para su fabricación. Las numerosas fuentes de materias primas son bastantes aptas para la talla laminar y para la realización del retoque plano. Estos serían los dos condicionantes para establecer los criterios de elección de un tipo de roca silícea sobre otra para la fabricación de los diferentes morfotipos de proyectiles $(H L, P A P$, $P M)$, ya que el retoque abrupto por presión en el filo del soporte en el caso de las PM no plantearía grandes problemas de ejecución. Pero se constata una tendencia a reservar el sílex jaspeado, sobre todo el melado, para las PAP. Muy probablemente esto sea debido a las mayores dificultades técnicas en su fabricación (Muñoz y Ripoll, 2001), una mejor respuesta de este al retoque por presión -con levantamientos mas profundos- y una mayor cercanía al yacimiento de las fuentes de silex criptocristalino.

La relativa abundancia de materia prima permite la elección de soportes de una calidad aceptable. Las impurezas y las fisuras que presentan los proyectiles no son relevantes en el total del conjunto. Las impurezas normalmente son de pequeño tamaño y no tienen gran incidencia en el proceso de transformación. Los escasos valores que alcanzan las puntas craqueladas y cuarteadas junto con la escasa representación que tienen los subtipos que han sufrido alteraciones térmicas, sílex rojo y negro, parecen indicar la ausencia de un tratamiento térmico previo de la materia prima para la obtención del retoque plano. La aparición de elementos desilificados, craquelados y cuarteados se debe a su posición en el interior de las estructuras de combustión y no a un calentamiento intencional y controlado. Como se desprende del 
estudio microespacial de la dispersión de restos del yacimiento, normalmente los proyectiles solutrenses aparecen en el centro de los hogares y los desechos de talla en la zona marginal de los mismos, (Ripoll, S. 1988).

\section{SOPORTES}

Las características tecnológicas de los soportes sobre los cuales están realizadas las puntas de proyectil son un dato fundamental para el estudio de las mismas, ya que la elección de un determinado tipo condicionará en gran medida sus atributos volumétricos y la disposición de sus elementos. Los foliáceos bifaciales están realizados fundamentalmente sobre lascas $(52,69 \%)$, en menor medida sobre hojas $(26,88 \%)$ y un $20,43 \%$ del total corresponde a fragmentos no identificables (fig. 2 y figs. 9-12). El dominio de las lascas sobre los soportes laminares es especialmente significativo en las PSB (96,15\% frente al 3,85\%), donde no hay fragmentos no identificables. A media que avanzamos en el proceso de reducción bifacial el número de puntas realizadas sobre hojas aumenta de forma importante. Así, en las HLna su valor es del $20,00 \%$ y en las HL es del $33,08 \%$, mientras que las piezas sobre lascas representan el $63,33 \%$ y el $41,54 \%$ respectivamente. Estos datos demuestran que uno de los factores que determinan el abandono de las prefor- mas es el soporte elegido. Aquellos proyectiles que se realizan sobre hojas tienen una mayor probabilidad de terminar el proceso de fabricación de forma satisfactoria, posiblemente porque necesitan una menor reducción bifacial y una percusión menos violenta para conseguir levantamientos profundos o invasores en sus fases iniciales. Una caracteristica inherente a la PM es su elaboración sobre soportes laminares, fundamentalmente hojas $(98,98 \%)$, por lo que no es factible establecer una comparación con este tipo de puntas, (Muñoz, 2000). Pero en el caso de las PAP sí se observa una preferencia contraria a los foliáceos bifaciales, ya que los soportes laminares alcanzan el 57, 15\% (Muñoz, 2000).

En cuanto a la presencia de córtex en las superficies de los proyectiles el $23,12 \%$ del total son de segundo orden y el $76,88 \%$ de tercer orden, (fig. 2). Lógicamente, en las PSB hay una mayor proporción de piezas con restos de córtex (38, $46 \%)$ que en las HL.na $(23,33 \%)$ y que en las HL $(20 \%)$, ya que el proceso de reducción bifacial está en sus fases iniciales, (fig. 9: 5 y fig. 12: 11). Mientras que en las PAP la totalidad de la muestra se corresponde con productos de tercer orden (Muñoz, 2000), sólo el 80\% de las HL pertenecen a esta categoría. Hay 14 piezas que presentan restos de córtex en anverso y en reverso, de las que sólo 2 corresponden a PSB y una $\mathrm{HL}$ tiene córtex en el reverso. Asimismo, todos los soportes elegidos carecen de accidentes de talla: sólo una PSB

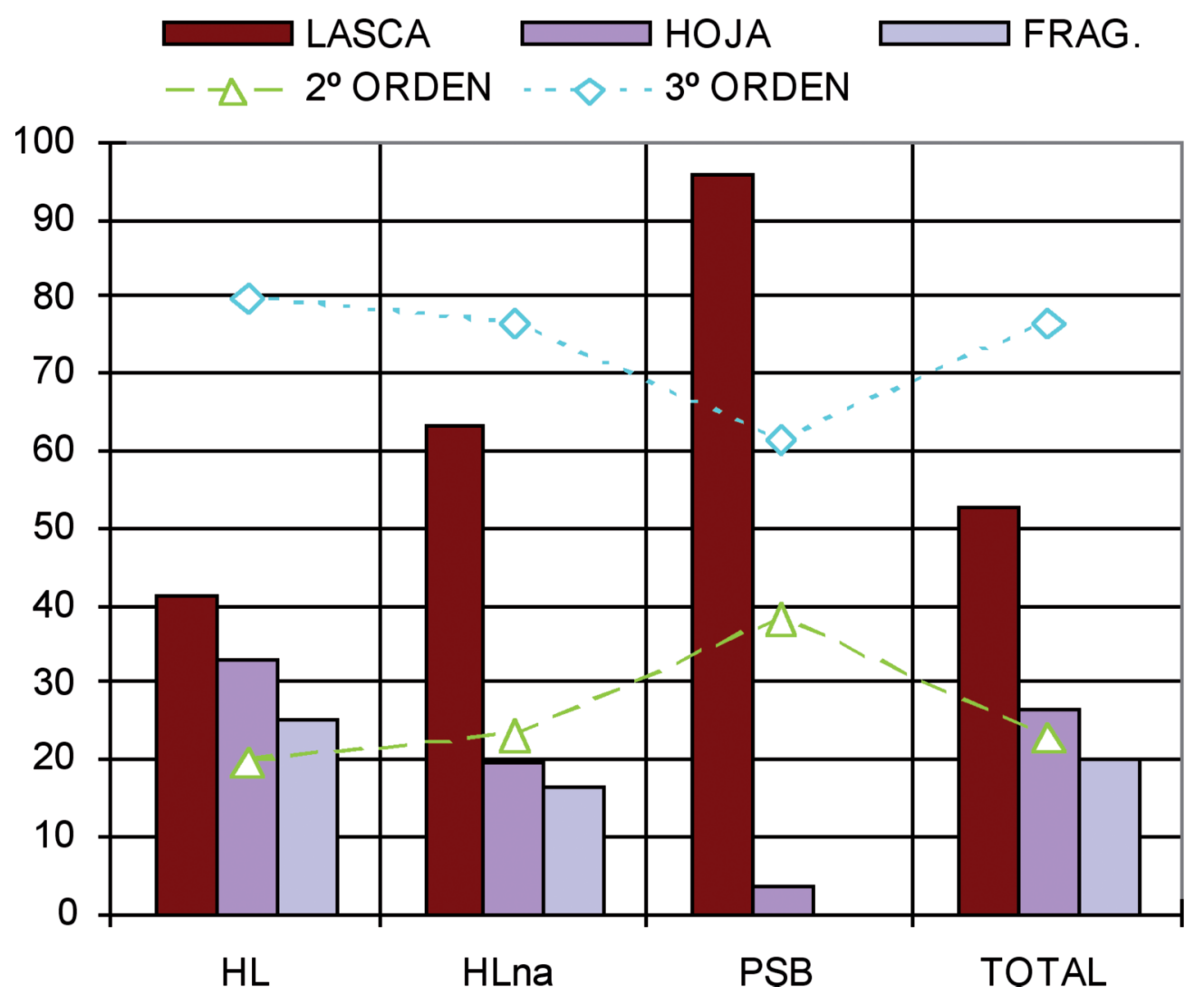

A Figura 2. Tipos y orden de los soportes. 

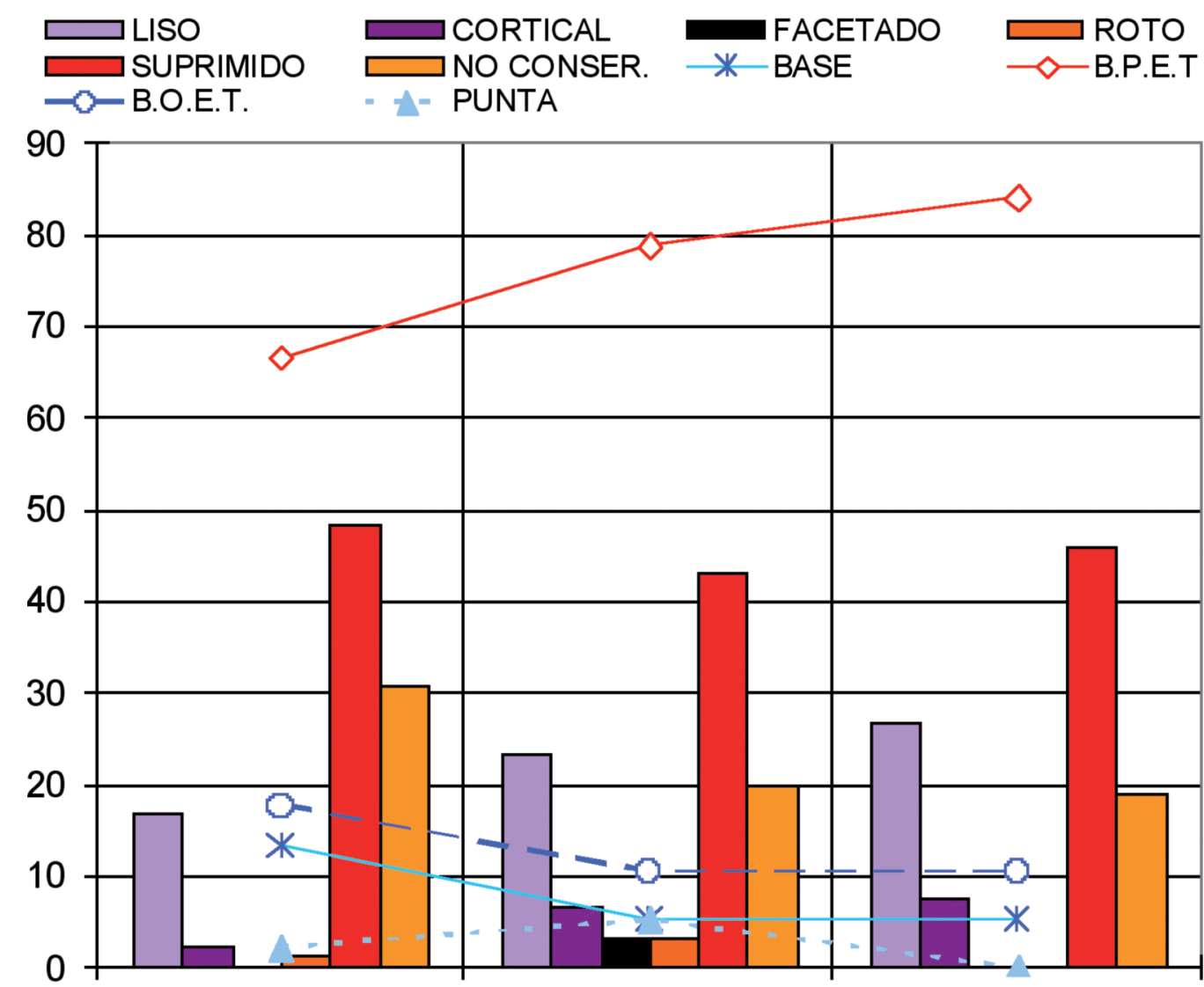

$\mathrm{HL}$

HLna

PSB

A Figura 3. Tipos de talones y su orientación con respecto al proyectil. BPET: Base paralela al eje tecnológico. BOET: Base oblicua a eje tecnológico.

está sobrepasada y una HL presenta una ligera torsión longitudinal, similar en su morfología a un golpe de buril.

Estos datos revelan que hay una cuidadosa elección de los soportes en función de las estrategias utilizadas en la reducción de los núcleos, con un aprovechamiento casi intensivo y sistemático de las zonas más próximas al área cortical. En algunas ocasiones se eligen soportes con restos de córtex que el retoque plano e invasor no es capaz de eliminar totalmente; a pesar de la cantidad y calidad de la materia prima existente en el área de captación del yacimiento. Esta táctica en la gestión y elección de soportes es similar a la llevada a cabo con las PAP (Muñoz, 2000).

En la mayor parte de los proyectiles bifaciles el talón ha sido eliminado de forma intencional por el retoque (47,31\% de talones suprimidos). En un 27,42\% este elemento no se ha conservado debido a los procesos de fracturación. Los proyectiles cuyo talón es identificable suponen el $23,66 \%$. En este caso dominan los lisos (19,35\%), seguidos de los corticales $(3,76 \%)$ y sólo el $0,54 \%$ son facetados. En el 1,61\% de los casos está roto. En líneas generales estas proporciones se mantienen en las tres categorias (fig. 3), aunque naturalmente en las PSB $(46,15 \%)$ y HL.na $(43,33 \%)$ el porcentaje de talones suprimidos es menor que en las $\mathrm{HL}$
(48,46\%). Asimismo, en las PSB únicamente hay talones lisos $(26,92 \%)$ y corticales $(7,69 \%)$. La importancia de los talones lisos va disminuyendo a medida que nos acercamos al final del proceso de fabricación. Así, en las HL.na suponen el $23,33 \%$ del total y en la HL el 16,92\%. Estos datos contrastan con los que proporcionan las PM (4,08\% liso, 40,81\% suprimido y $55,11 \%$ no conservado) y las PAP $(4,76 \%$ suprimido y $95,24 \%$ no conservado), (Muñoz, 2000). Esta diferencia de porcentaje de talones conservados implica una mayor preocupación en las puntas ligeras por obtener una morfología proximal lo más regular posible, que garantice un enmangue óptimo es un astil de un diámetro mucho menor que en las HL. Por lo tanto, este es otro dato que vuelve a indicar la funcionalidad de las PAP y PM como puntas de flecha en contraposición a las HL como puntas destinadas a ser lanzadas con propulsor o enmangadas en jabalinas.

La naturaleza de los talones conservados indica que no hay una preparación previa para destacar el punto de impacto de la superficie de percusión o presión a la hora de extraer los soportes. Este rasgo, común a los diferentes proyectiles solutrenses, indicaría la que la técnica más habitual para la obtención de los soportes sería la presión y la percusión directa con percutor blando. La mayoría de las 


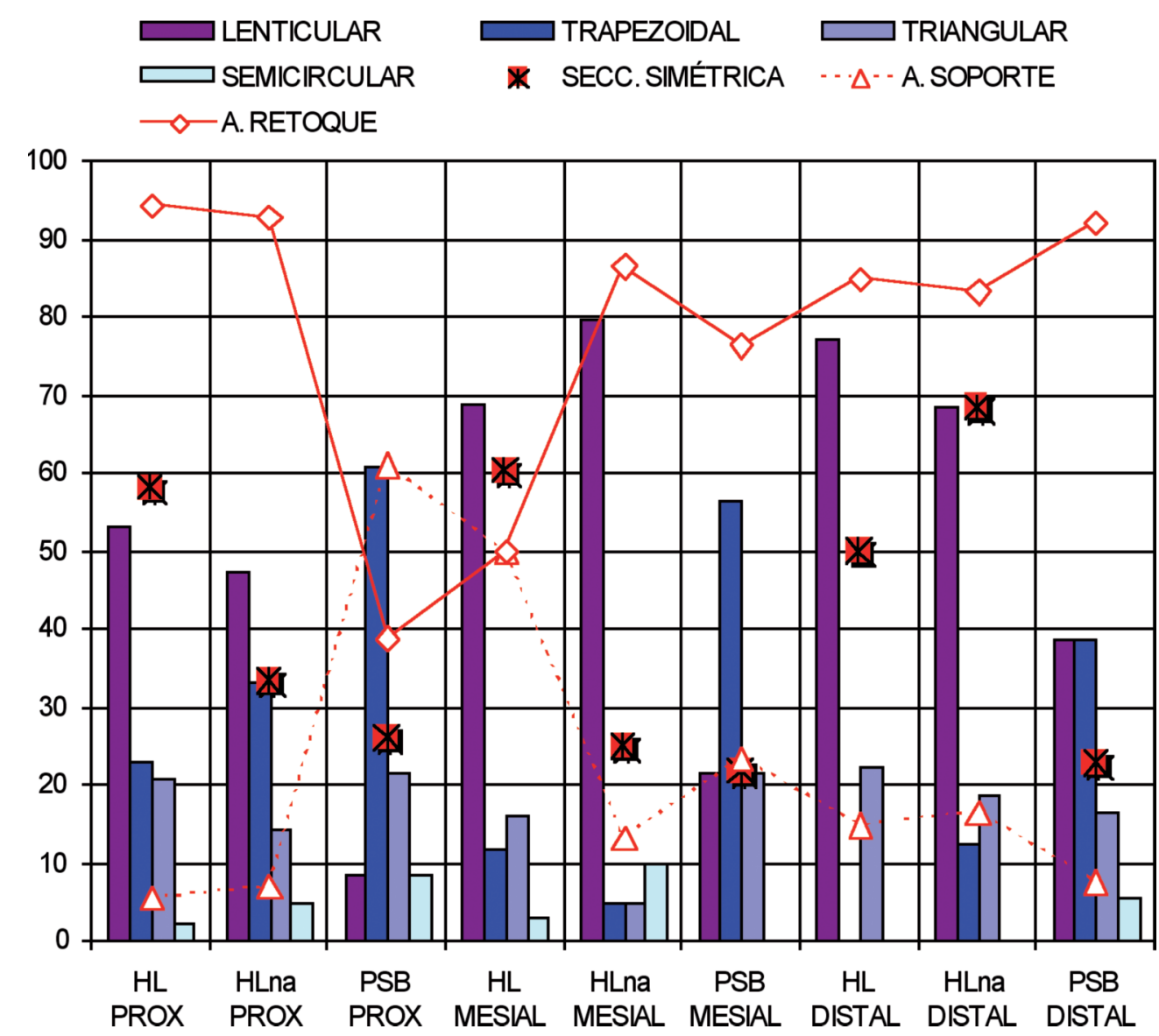

A Figura 4. Morfología y simetría de las secciones transversales. A. Soporte: asimetría causada por el soporte. A. Retoque: asimetría causada por el retoque. El porcentaje de estas dos últimas variables está calculado en relación al total de secciones asimétricas.

puntas cuyo reverso no ha sido modificado muestran bulbos poco prominentes y ondas de percusión distanciadas y poco marcadas. La presencia de talones corticales en proyectiles, cuyo proceso de elaboración ha concluido, es otro argumento que indicaría la elección de las zonas más externas de los nódulos para obtener los soportes característicos. La supresión del talón junto con el bulbo permite un enmangue óptimo y un reverso lo más regular posible.

En la mayoría de las ocasiones el talón, con respecto al proyectil, se ubica en el extremo proximal del mismo (fig. 3). Cuando éste no se encuentra presente, en una gran parte de las ocasiones su situación dentro del soporte se ha conseguido a partir de las ondas de percusión. Solo en dos piezas $(2,41 \%)$ aparece en la punta. Se trata de una PSB y una HLna; por lo tanto, piezas no terminadas, donde la morfología específica del soporte ha obligado al tallador a invertir la distribución de sus elementos bien por la presencia de accidentes de talla (sobrepasados o reflejados) o por los valores volumétricos (espesor del extremo distal). La mayor parte de los talones situados en el extremo proximal son paralelos al eje tipológico de la pieza $(73,49 \%)$ y en menor medida oblicuos $(14,46 \%)$. Estos últimos se corresponden con puntas realizadas sobre lascas. En el 9,64\% de la muestra únicamente se ha podido determinar que el talón se sitúa en el extremo proximal pero sin poder precisar su orientación.

La configuración de los soportes junto con la naturaleza de los procesos de transformación de los mismos está íntimamente relacionada con la morfología que adquieren los proyectiles en las diferentes etapas de fabricación (fig. 4). En las $\mathrm{HL}$ dominan las secciones transversales lenticulares tanto en la zona proximal $(53,49 \%)$, como en la mesial $(69,12 \%)$ y la distal (77,50\%), como consecuencia del retoque plano y bifacial, al igual que en las HL.na: proximal $47,62 \%$, mesial $80 \%$ y distal $68,75 \%$, (figs. 10-12). En las PSB las secciones trapezoidales son las más numerosas tanto en la zona proximal $(60,87 \%)$ como en la mesial $(56,52 \%)$, mientras que en las distales un $38,89 \%$ son lenticulares y un $38,89 \%$ son trapezoidales (fig. 9). Las secciones lenticulares serían las más características del empleo del retoque plano, invasor y bifacial. Las semicirculares se corresponden con piezas de escaso grosor y reverso totalmente plano, que no requieren una gran transformación. En las secciones triangulares los levantamientos del anverso no llegan a ser totalmente invasores, creando una pequeña arista en el eje longitudinal del proyectil. En las secciones trapezoidales el ángulo de los le- 
vantamientos del anverso es superior a los $45^{\circ}$ y éstos no llegan a ser totalmente invasores.

La morfología que adoptan los proyectiles en la zona de enmangue tiene una cierta variabilidad en todas las categorías. Esta versatilidad se mantiene en las secciones mesiales de las PSB y en menor medida en las distales. Sin embargo, en las HL y HL.na hay una amplia mayoría de formatos lenticulares, y en menor medida triangulares, a partir de la mitad superior del proyectil. Por lo tanto, uno de los objetivos de los procesos reductivos, además de adelgazar la pieza, es obtener una forma lo más aerodinámica posible en esta área de al pieza. El retoque en la zona de enmangue sería menos preciso y esto nos hace suponer, nuevamente, que el diámetro de los astiles donde quedan insertadas las puntas permite adaptar al mismo formas y grosores diversos.

La mayor parte de las secciones son asimétricas, aunque a medida que avanzamos hacia el final del proceso de fabricación este porcentaje desciende, (fig. 4). Así, en las HL las secciones asimétricas oscilan entre el 39,70 y el 50\% del total, en las HL.na entre el 37,50 y el $75 \%$ y en las PSB entre el 72,22 y el $78,26 \%$. Los valores más bajos coinciden con la zona dista, salvo en las PSB donde los valores son muchos más altos y están muy agrupados. La mayoría de las secciones son asimétricas debido al retoque, salvo en la zona proximal de las PSB y la mesial de las HLna. Por lo tanto, hay un mayor interés en conseguir que las piezas acabadas tenga una sección simétrica a partir de los 2/3 superiores de la pieza, lo que muy probablemente podría estar relacionado con una mejor aerodinámica y capacidad de penetración. Asimismo, con estos datos podemos suponer que el tercio inferior del proyectil quedaría embutido en el astil y por tanto la morfología y simetría de su sección es menos importante. Por ejemplo, en el caso de las PAP, las secciones de la zona activa, es decir, excluido el enmangue son mayoritariamente lenticulares $(78,58 \%)$ y simétricas $(94,59 \%)$, (Muñoz, 2000).

\section{5.- MORFOLOGÍA Y TIPOMETRÍA}

Las hojas de laurel son útiles bien individualizados dentro del tecnocomplejo solutrense. Desde los inicios de la investigación de este periodo han sido muchas las propuestas tipológicas para clasificar los foliáceos bifaciles en función de sus caracteristicas morfológicas y regionales. Sin embargo, son mucho menos numerosos los modelos que parten de un análisis formal de los diferentes elementos que conforman el proyectil para jerarquizarlos sobre bases tecnológicas y funcionales. La morfología que adoptan tanto la punta como la base y la delineación de los filos laterales serían los parámetros más importantes para este último tipo de estudios. La morfología del elemento de enmangue condiciona en gran medida los sistemas de sujeción al astil y, por lo tanto, tiene una repercusión en los procesos de fragmentación por uso. En las PSB el extremo proximal tiene forma convexa (50\%) o rectilínea $(45,45 \%)$ y en solo el 4,55\% triangular, (fig. 9). A medida que avanzamos en el proceso de fabricación se produce una mayor diversificación en las morfologías. Así, en las HL.na aunque siguen siendo mayoritarias la bases convexas $(56,52 \%)$, seguidas de las rectilíneas $(30,43 \%)$, un $13,04 \%$ son triangulares, (fig. 10). En las HL esta proporción llega al 26,67\%, mientas que las rectilíneas se mantienen $(30 \%)$ y las convexas descienden significativamente (38,89\%), (figs. 11-12). Por último, en 4 HL (4,44\%) el extremo proximal termina en forma de pedúnculo, (fig. 11:8). Estos datos apuntan a que la forma definitiva que adoptan las HL en su zona proximal se produce en la última etapa de fabricación y posiblemente estaría relacionada con la adecuación de la zona de enmangue a un astil de dimensiones concretas.

La zona distal de los proyectiles presenta únicamente dos variaciones formales. El extremo activo de la pieza es más o menos aguzado generando puntas ojivales (fig. 12: 4) o triangulares, (fig. 12: 11). Estas morfologías determinan en gran medida la capacidad de penetración en la posible presa, ya que las primeras forman un ángulo mucho más abierto que las segundas. Aunque a priori las puntas ojivales tienes menos posibilidades de alcanzar órganos vitales, la mayor anchura de la punta puede provocar heridas más grandes. Durante el proceso de fabricación se parte de morfologías fundamentalmente ojivales en las PSB (89,47\%), debido a la escasa transformación del soporte, hasta llegar en las HL a un $77,50 \%$ de puntas triangulares. En las HL.na los valores se reparte de forma uniforme entre ambas categorías (52,94\% triangulares y $47,06 \%$ ojivales). La media aritmética del ángulo que presenta la punta en las piezas acabadas es de $29^{\circ}$, con una amplitud de valores que abarca desde los $45^{\circ}$ a los $17^{\circ}$. En más de la mitad de la muestra $(57,50 \%)$ el ángulo de la punta se sitúa entre los $21^{\circ}$ y los $30^{\circ}$ y solo el $12,50 \%$ es menor de $20^{\circ}$. Estas cifras son sensiblemente superiores a las que arrojan las PAP (Muñoz, 2000), con una media aritmética de $17,23^{\circ}$, con valores extremos de $30^{\circ}$ y $6^{\circ}$ y sólo el $29,41 \%$ supera los $20^{\circ}$. En las PM la media aritmética del ángulo de la punta es algo mayor $\left(21,8^{\circ}\right)$. Los proyectiles se sitúan entre los $10^{\circ}$ y $40^{\circ}$, pero el $48,61 \%$ no supera los $20^{\circ}$ (Muñoz, 2000). La capacidad de penetración de las HL es sensiblemente inferior a las puntas ligeras de proyectil, por lo tanto su eficacia cinegética estaría basada en la capacidad de provocar heridas amplias y masivas con pérdida importante de sangre frente a la estrategia de las PAP y PM de alcanzar órganos o arterias vitales.

Los filos laterales de las $\mathrm{HL}$ con fundamentalmente convexos $(76,81 \%)$ y en menor medida rectos $(21,01 \%)$. Estos últimos corresponden en su gran mayoría con piezas realizadas sobre soportes laminares que tienen extremos distales triangulares. Además en tres piezas estos filos son sinuosos. Se parte fundamentalmente de soportes con bordes convexos $(84,62 \%$ en las PSB) y en su inmensa mayoría se man- 


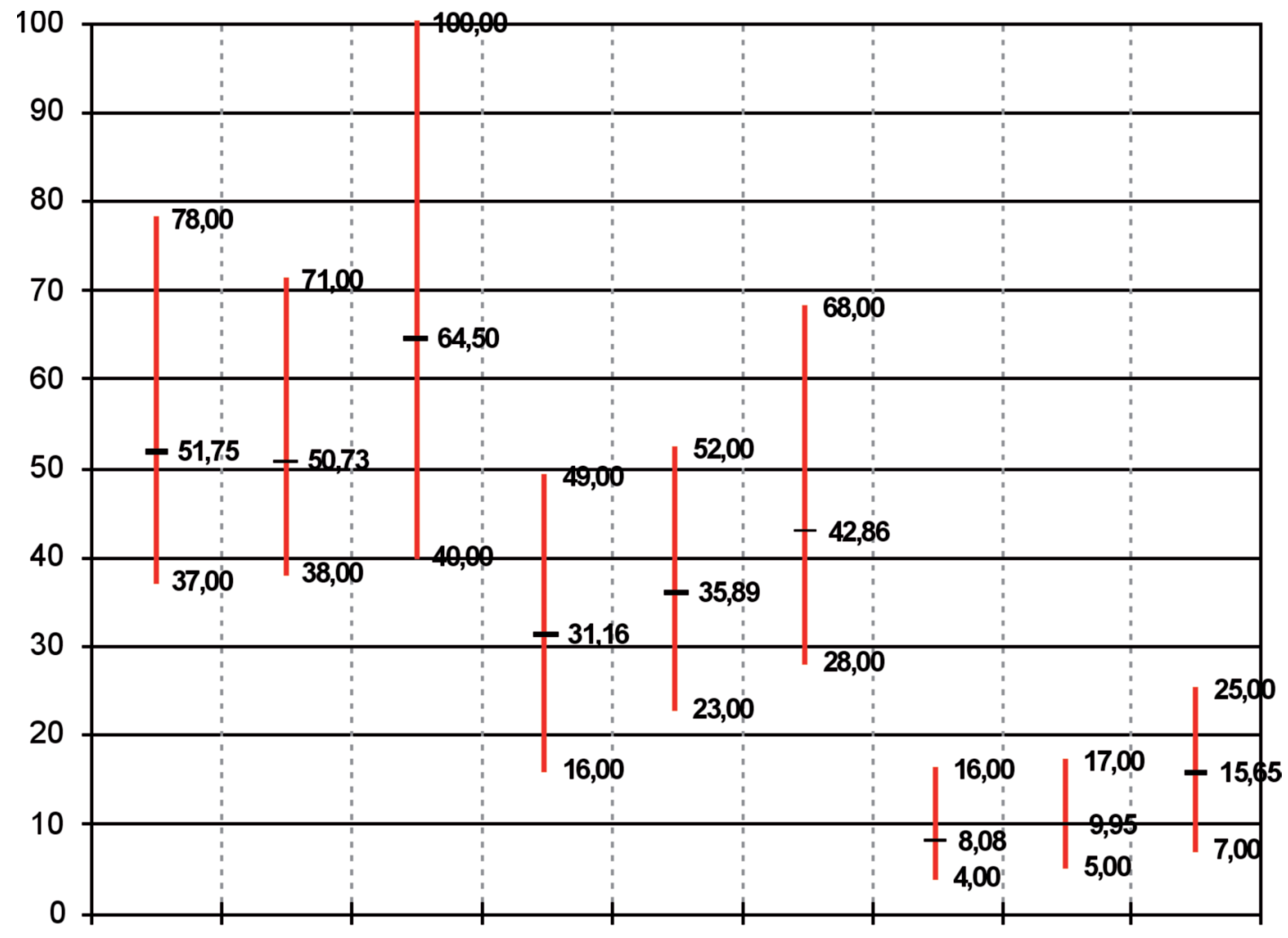

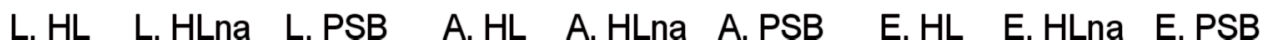

A Figura 5. Longitud, anchura y espesor máximos expresados en mm.

tiene esta morfologia en la pieza acabada, aunque reduciendo considerablemente la convexidad inicial.

Si se tienen en cuenta los tres parámetros que definen el volumen de estas puntas de proyectil (longitud, anchura y espesor máximos), hay una gran variabilidad en la amplitud de los valores extremos que llegan a alcanzar, aunque si hay una tendencia al agrupamiento de la mayor parte de la población en los valores intermedios (fig. 5). La media aritmética de las dimensiones que tienen los soportes de los que se parte para su fabricación (PSB) es de 64,50 mm de longitud (el 56,25\% se incluye dentro del intervalo $51-70 \mathrm{~mm}), 42,86 \mathrm{~mm}$ de anchura (63,63\% en el intervalo $31-50 \mathrm{~mm}$ ) y 15,65 de espesor (65,21 en el intervalo 11-20 mm). En las HL.na se produce una pérdida muy significativa del grosor de los mismos: la media aritmética pasa a 9,95 mm y el 52,63\% se sitúa entre 6 y 10 $\mathrm{mm}$. Esto supone casi una reducción media del 36,52\%. La disminución en la longitud del soporte es menor, un 21,35\%, ya que la media aritmética es de $50,73 \mathrm{~mm}$ y el $81,81 \%$ se sitúa en el intervalo 41-60 mm. La anchura de las HLna es la que sufre menos variaciones con respecto a las PSB. Su media aritmética es de $35,89 \mathrm{~mm}$, lo que supone una disminución del $16,26 \%$. El $68,42 \%$ de las piezas tiene una anchura que oscila entre los $21 \mathrm{~mm}$ y $40 \mathrm{~mm}$. En las HL apenas hay cambios significativos en el grosor y la longitud con respecto a las HL.na. La media aritmética del espesor es de $8,08 \mathrm{~mm}$ y el $64,17 \%$ tiene entre $6 \mathrm{~mm}$ y $10 \mathrm{~mm}$ como en las HL.na. En cuanto a la longitud la media aritmética incluso sube ligeramente hasta los $51,75 \mathrm{~mm}$ y el intervalo más numeroso es el de $41-50 \mathrm{~mm}$, donde se incluye el $41,66 \%$ de la muestra de estudio. La anchura final que alcanzan estas puntas es un $13,18 \%$ inferior a las HL.na, con una media aritmética de $31,16 \mathrm{~mm}$ y donde el $54,10 \%$ tiene entre $21 \mathrm{~mm}$ y $30 \mathrm{~mm}$.

El tamaño de los soportes empleados en la fabricación de este tipo de proyectiles experimenta una considerable disminución durante el proceso de talla bifacial. Así, las HL con respecto a las PSB son un 19,77\% más cortas, un 27,30\% mas estrechas y un 48,37\% más delgadas. La mayor pérdida de volumen se produce en el paso de PSB a HL.na, sobre todo en lo que respecta a la longitud y al espesor. La anchura presenta una disminución más progresiva a lo largo de todas las etapas de trabajo. Los datos de la tipometría de estas puntas permiten hablar de la existencia de una cierta estandarización en su manufactura, aunque menor que en las PAP y PM. Si en las puntas ligeras de proyectil las técnicas de ta- 
lla empleadas en la extracción de los soportes están encaminadas a dar una determinada uniformidad a la producción, salvando las distintas propiedades mecánicas de las materias primas empleadas, en las HL esta semejanza se consigue fundamentalmente mediante el retoque bifacial.

La relación que se establece entre las diferentes magnitudes permite clasificar las puntas según su Índice de Aplanamiento (Longitud Total/Espesor Máximo) y su İndice de Alargamiento (Longitud Total/Anchura Total) en diferentes categorías, (Muñoz, 2000):

Puntas muy delgadas:

(l. de Aplanamiento $>12=<8,33 \%$ de la longitud total). Puntas delgadas:

(l. de Aplanamiento $\leq 12$ y $8 \geq=\geq 8,33 \%$ y $€ 12,5 \%$ de la longitud total)

Puntas espesas:

(l. de Aplanamiento $<8=>12,5 \%$ de la longitud total). Puntas estrechas:

(I. de Alargamiento $>3=<33,33 \%$ de la longitud total). Puntas anchas:

(I. de Alargamiento $\leq 3$ y $\geq 2=\geq 33,33 \%$ y $\leq 50 \%$ de la longitud total).

Puntas muy anchas:

(l. de Alargamiento $<2=>50 \%$ de la longitud total).
En $13 \mathrm{HL}$ (10\%) ha sido posible calcular el Índice de Aplanamiento. Solo una pieza entraría dentro de la categoría "muy delgada", 2 son delgadas y el resto son espesas. El Índice de Alargamiento da como resultado 12 puntas estrechas y 1 punta ancha. Las puntas ligeras de proyectil son mayoritariamente delgadas o muy delgadas (70,59\% PAP y $100 \%$ PM) y anchas o muy anchas (93,75\% PAP y $82,86 \%$ PM), (Muñoz, 2000); es decir, se da una inversión total de valores ya que estos tipos de proyectiles son significativamente más anchos y delgados en relación a su longitud.

La pérdida de materia en las diferentes fases de trabajo tiene una repercusión directa en el peso que alcanzan las diferentes categorías. Lógicamente se han tenido en consideración solo las piezas que no presentan fracturas. Esto ha reducido de forma importante el número de ejemplares: 7 HL, 11 HL.na y 14 PSB. La media aritmética del peso de los diferentes tipos es proporcional a la reducción media de volumen. Así, el peso medio de las PSB es de 45,54 g. con una amplitud de valores que oscila entre los 138,4 y $12,8 \mathrm{~g}$. En la HLna la media aritmética del peso es significativamente menor $(12,63 \mathrm{~g})$ y también el valor máximo $(28,5 \mathrm{~g})$ y el mínimo $(5,8 \mathrm{~g})$, es decir, se ha producido una reducción media del peso inicial de los soportes del 72,26\%. En la HL los valores son solo ligeramente inferiores a las HL.na, con una media de $10,29 \mathrm{~g}$ y una amplitud de 16,5 y $4,1 \mathrm{~g}$. En el caso de las PAP

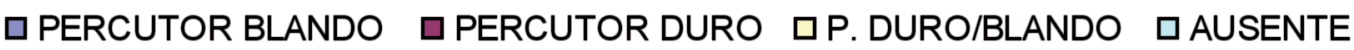

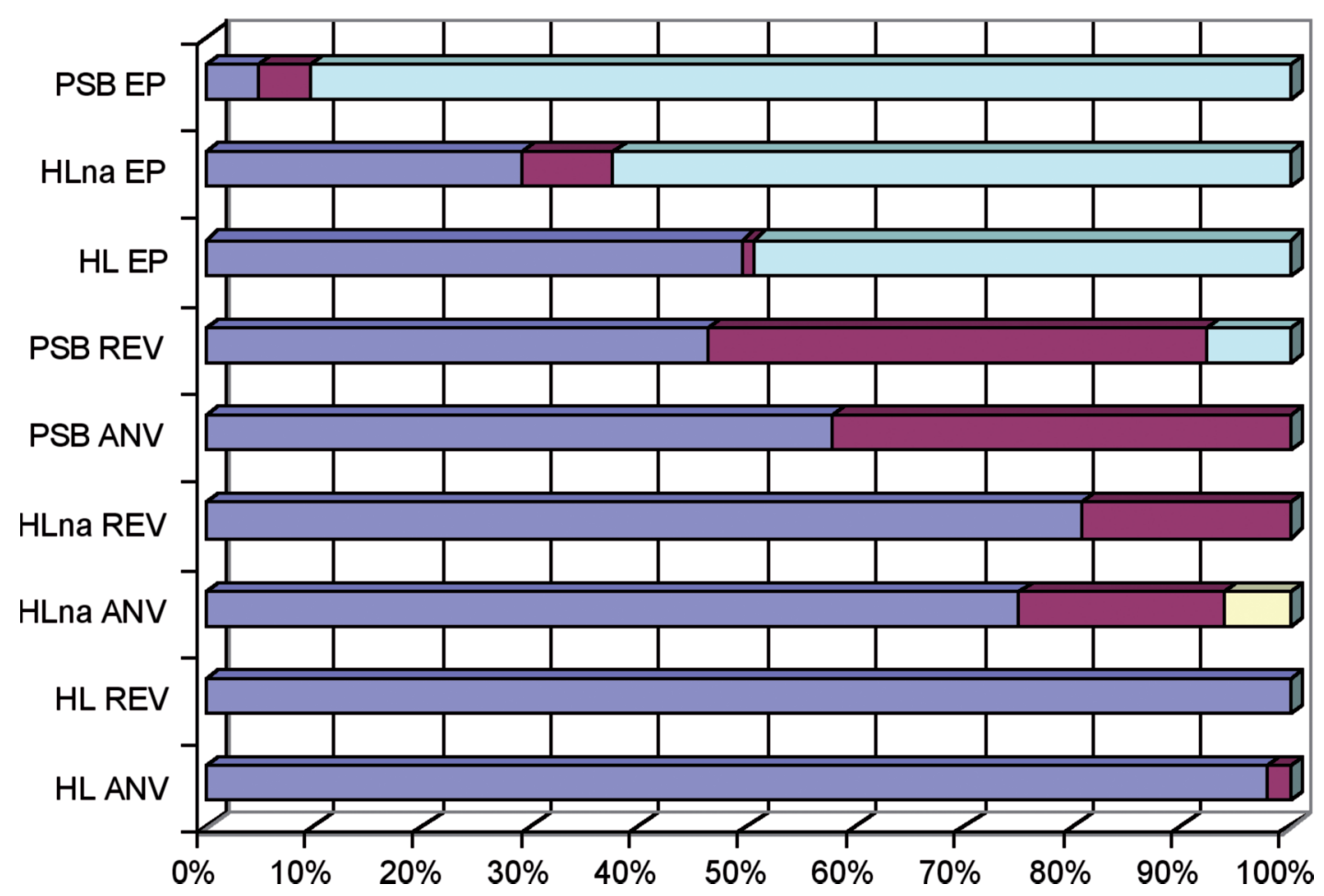

- Figura 6. Técnicas de talla empleadas en el proceso de reducción bifacial. 
la media es de $1,33 \mathrm{~g}$, siendo el proyectil más ligero de tan solo $0,31 \mathrm{~g}$ y el más pesado de $3,5 \mathrm{gr}$. En las puntas de muesca es de $0,76 \mathrm{~g}$, con valores máximos y mínimos que oscilan entre los 5,9 gr y los 0,1 gr. Estos datos atestiguan que en la inmensa mayoría de las ocasiones el peso de ambos tipos de proyectiles no superan los $5 \mathrm{~g}$, uno de los parámetros que tienen que cumplir las puntas de proyectil para ser consideradas puntas de flecha, (Muñoz, 2000). Sin embargo, todas las HL sobrepasan este peso máximo.

\section{ESQUEMA DE TRABAJO}

La reducción bifacial mediante percusión directa con percutor blando para obtener puntas de proyectil, como las $\mathrm{HL}$, es un proceso bien sistematizado desde el punto vista teórico, experimental y arqueológico, (Maillo, 1999; Baena, 1998; Callahan, 1996; Whittaker, 1994; Pelegrin, 1981). La sistematización de los "procesos de reducción" y la identificación de los gestos técnicos e instrumentos empleados ha llevado a algunos de estos autores a establecer diferentes etapas durante la reproducción experimental de foliáceos, hasta siete llega a individualizar Callahan. No obstante, es bastante difícil encuadrar cada pieza arqueológica en cada una de fases diferenciadas con el material experimental. De hecho, en el caso que nos ocupa sólo ha sido posible identi- ficar tres grandes procesos en la reducción progresiva de la pieza: adelgazamiento del soporte (PSB), aproximación a la morfología final (HL.na) y acabado (HL). En líneas generales, la transformación de los soportes seleccionados en HL puede realizarse mediante dos sistemas que no son excluyentes. El primero se basa en preparar un plano de percusión semiabrupto desde donde realizar el retoque de una cara del soporte (Fig. 9: 5). El segundo se fundamenta en levantamientos alternantes en cada uno de los filos, preparando de forma individualizada cada punto de impacto. En ambos casos, éste debe ser abrasionado para aumentar ligeramente el grosor del filo, reforzar este punto y evitar así accidentes de talla. Estas dos estrategias aparecen representadas en las piezas no acabadas, aunque en el segundo caso no se producen extracciones alternantes, sino que siempre se empieza a retocar el anverso, (Fig. 9: 1). Las morfologías no deseadas durante el proceso de reducción se relacionan con desviaciones de la sección y aparición de caras cóncavas o planas (Baena, 1998). Para corregir estos accidentes de talla es necesaria una modificación del contorno definitivo de la pieza, que se traduce en una reducción de la anchura. El análisis de las secciones, mayoritariamente lenticulares, y de la tipometría, con una media de un $27,30 \%$ de reducción de la anchura, muestra que el grado de conocimientos técnicos y pericia de estos talladores es bastante elevado.

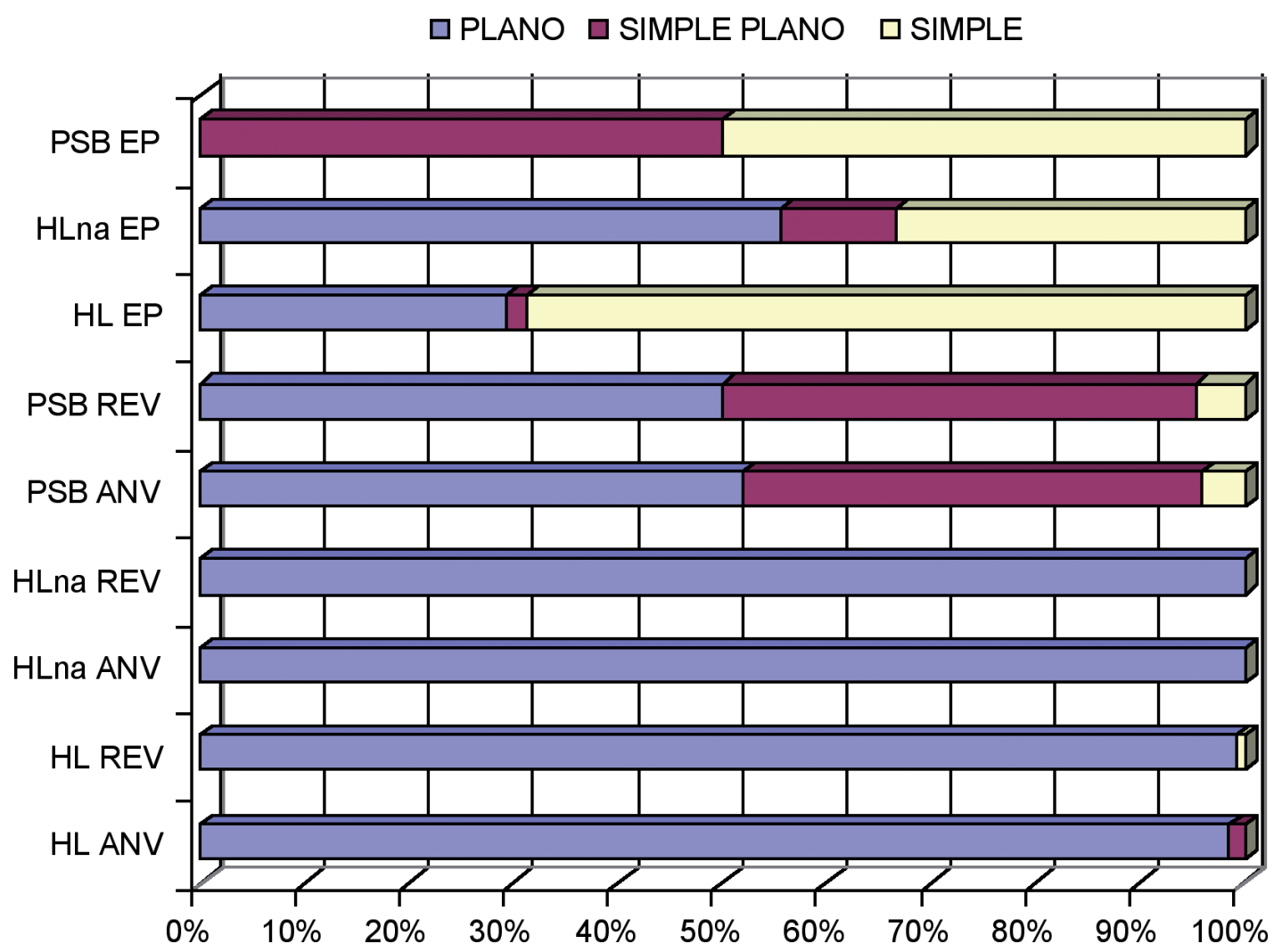

- Figura 7. Modo del retoque. 
口INVASOR 口PROFUNDO $\square$ NORMAL $\square$ MARGINAL

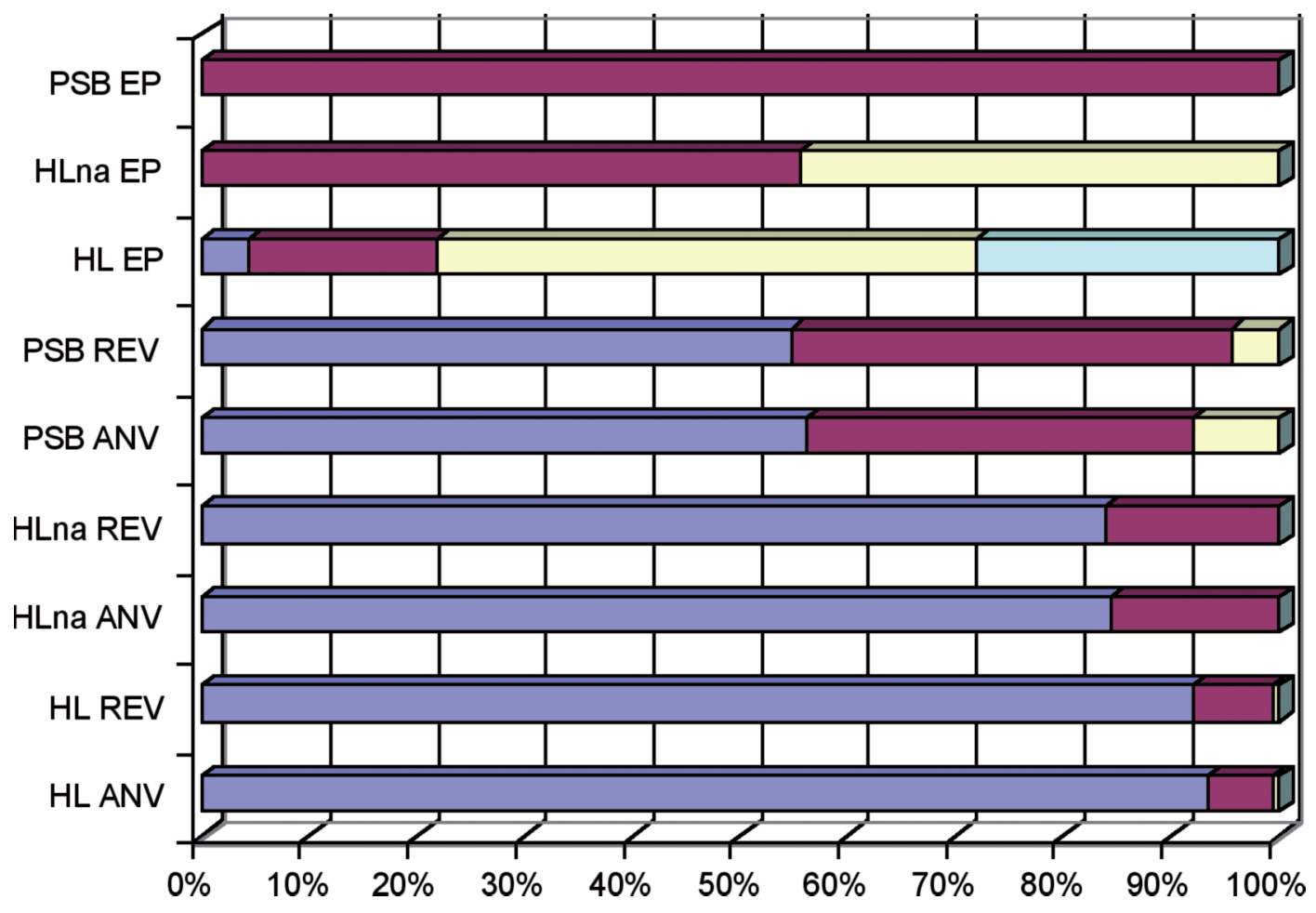

- Figura 8. Amplitud del retoque.

En las PSB el primer paso en su realización es el adelgazamiento del soporte seleccionado, (fig. 9). El proceso de transformación comienza por el anverso, ya que la cantidad de materia a eliminar para conseguir el grosor y la sección deseados es bastante importante, para posteriormente continuar por el reverso. Mientras que todas las PSB presentan extracciones en la cara dorsal hay un 7,69\% en cuya cara ventral el retoque está ausente (fig. 6). Éste se realiza mediante percusión directa con percutor duro y percutor blando en proporciones prácticamente similares tanto en anverso (57,69\% duro y 42,31 blando) como en reverso. $(46,15 \%$ en cada caso), (fig. 6). Aunque estos porcentajes hacen referencia a la técnica dominante en la mayor parte de los casos aparece una combinación de ambas en un mismo lado de la pieza. El modo de los retoques es fundamentalmente plano $(52,00 \%$ en anverso y $50,00 \%$ en reverso) y simple-plano $(44,00 \%$ y $45,45 \%$ respectivamente), (fig. 7$)$. Hay un pequeño número de piezas $(4,00 \%$ anverso y $4,55 \%$ reverso) donde los retoques son simples. En cuanto a su amplitud tanto en la cara dorsal como ventral dominan los levantamientos invasores $(56,00 \%$ y $54,55 \%)$, seguidos de los profundos $(36,00 \%$ y $40,91 \%)$ y en menor medida normales $(8,00 \%$ y $4,55 \%)$, (fig. 8). En esta primera etapa de transformación un $9,52 \%$ de las piezas presentan extracciones en el extremo proximal tanto con percutor duro como blando. Son retoques simples y simple-planos, todos ellos profundos. El retoque, en esta primera fase, estaría encaminado sobre todo a eliminar el córtex, crear dos superficies paralelas ligeramente convexas que permitan llegar a generar en fases posteriores secciones transversales simétricas y de tendencia lenticular y adelgazar el grosor del soporte. La silueta de la pieza al final de esta fase tiene una importancia secundaria, aunque se mantiene la preferencia por bordes convexos.

En las HL.na (fig. 10), el uso del percutor blando tanto en anverso $(75,00 \%)$ como en reverso $(80,65 \%)$ es netamente superior al empleo del percutor duro (18,75\% y $19,35 \%)$. En un $6,26 \%$ de los casos en la cara dorsal se emplea de forma indistinta las dos técnicas (fig. 6). En esta etapa la totalidad de los retoques son planos y fundamentalmente invasores $(84,38 \%$ en anverso y $83,87 \%$ en reverso). El resto son profundos (fig. 7). El 37,50\% de las piezas tiene extracciones en el extremo proximal obtenidas con percutor blando (29,17\%) y duro (8,33\%). Son levantamientos planos (55,56\%), simples $(33,33 \%)$ o simple-planos $(11,11 \%)$, cuya amplitud es profunda $(55,56 \%)$ o normal $(44,44 \%)$, (fig. 8). Al final de esta fase de la reducción bifacial el grosor y longitud que alcanza la pieza es ligeramente superior al definitivo, el córtex que no se ha eliminado permanecerá total o parcialmente en la pieza aca- 


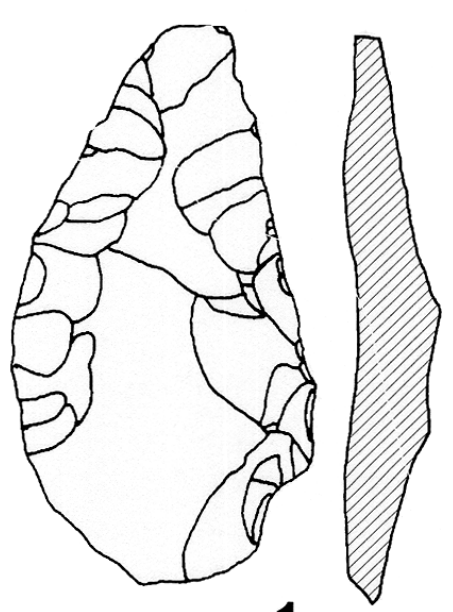

1

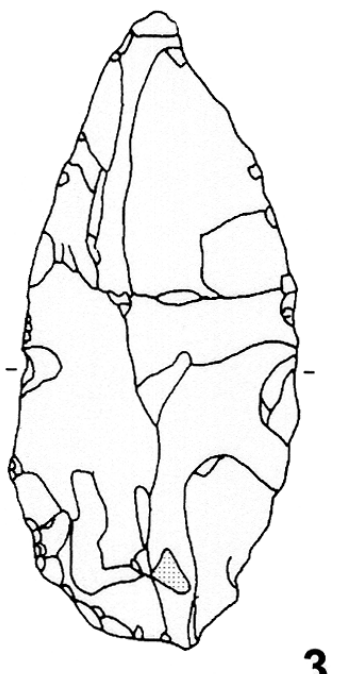

3

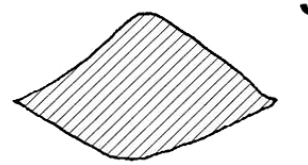

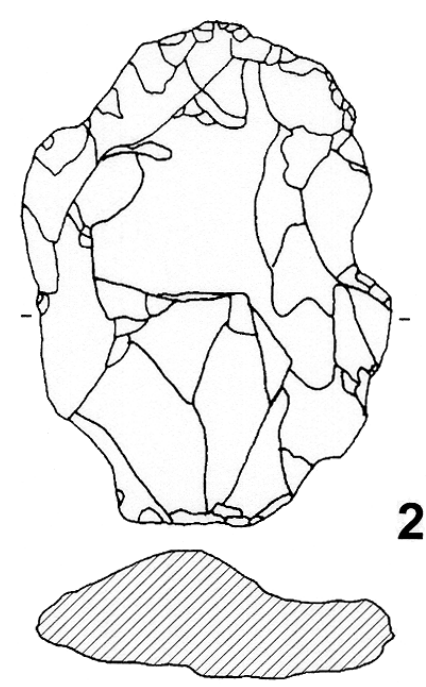
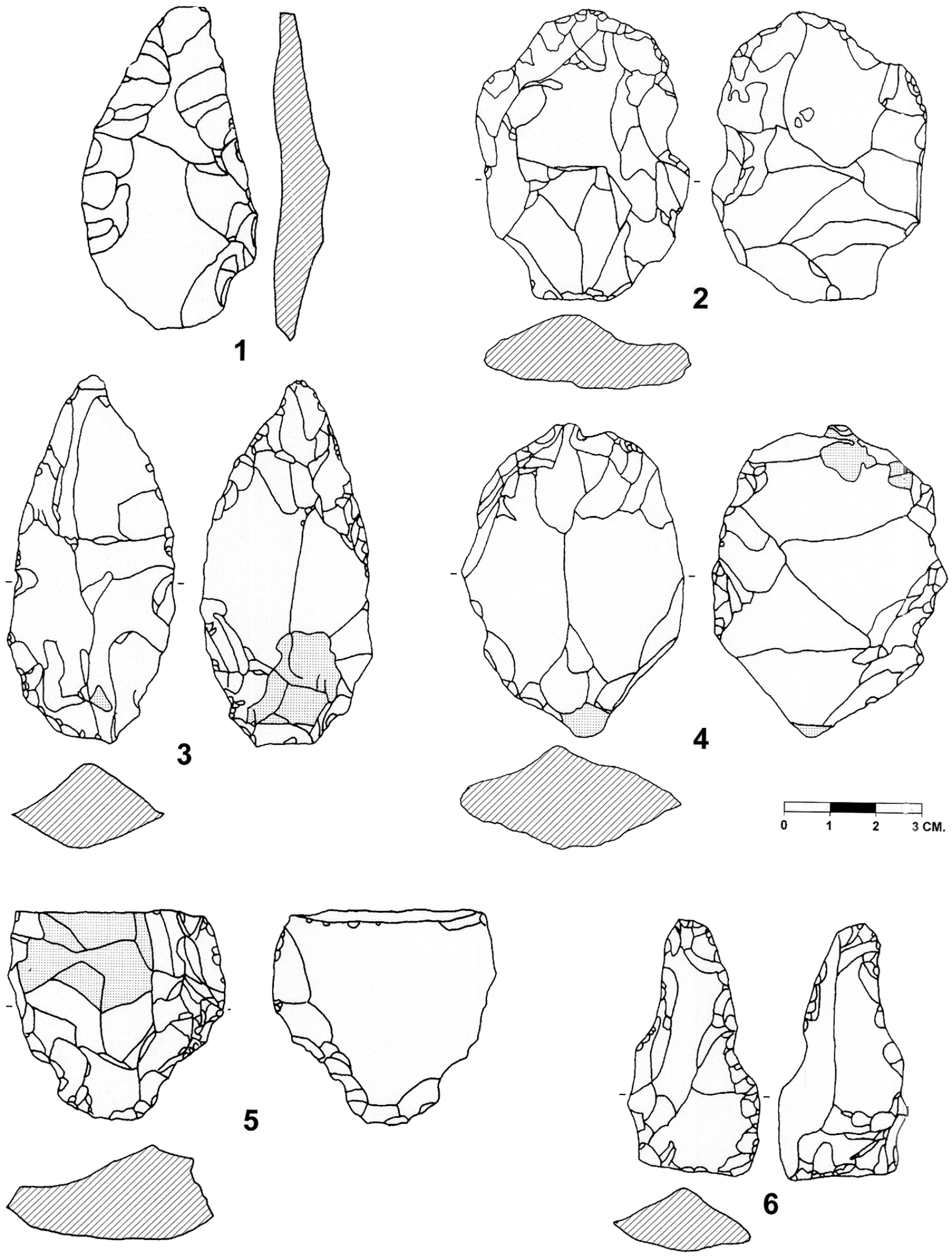

A Figura 9. Piezas solutrenses bifaciales (PSB). 

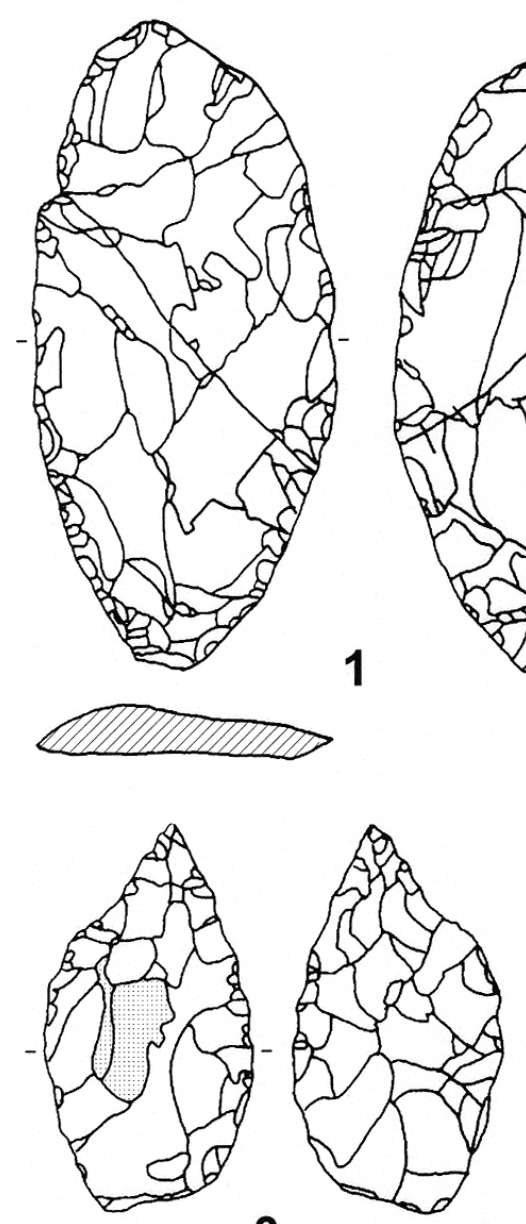

3
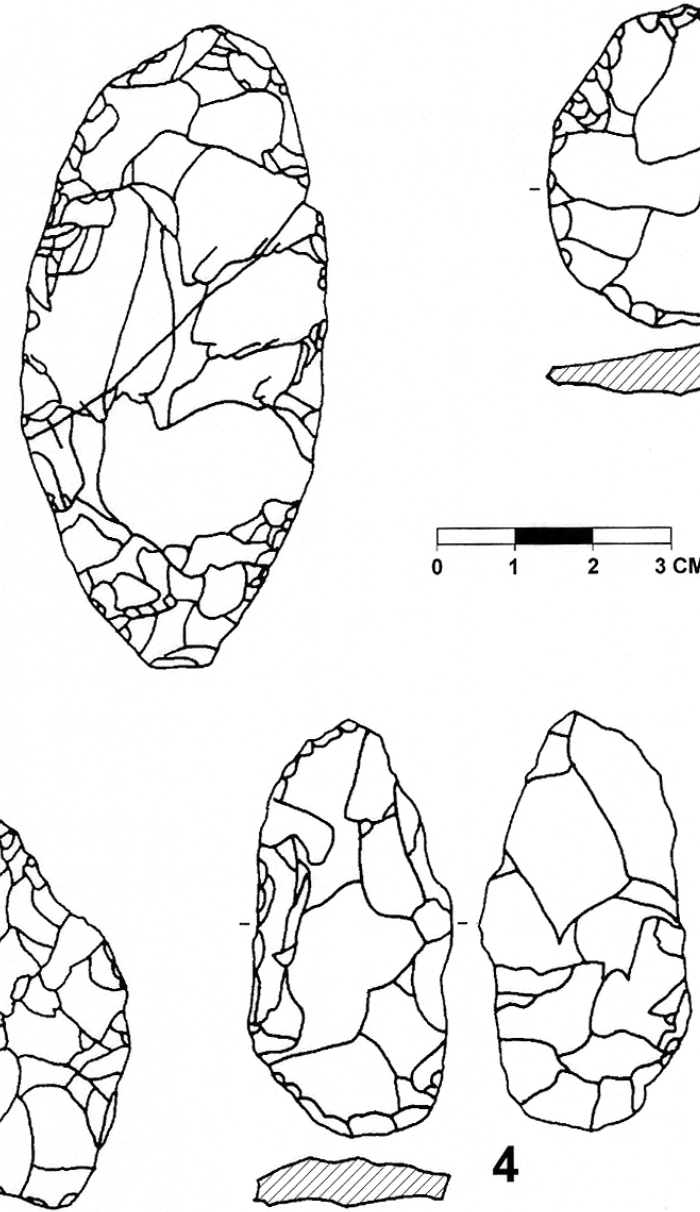

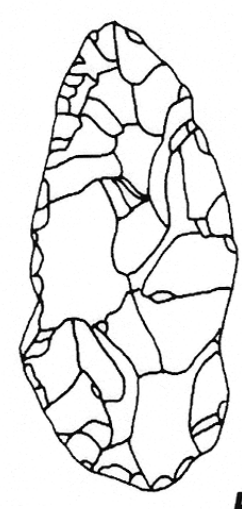

5
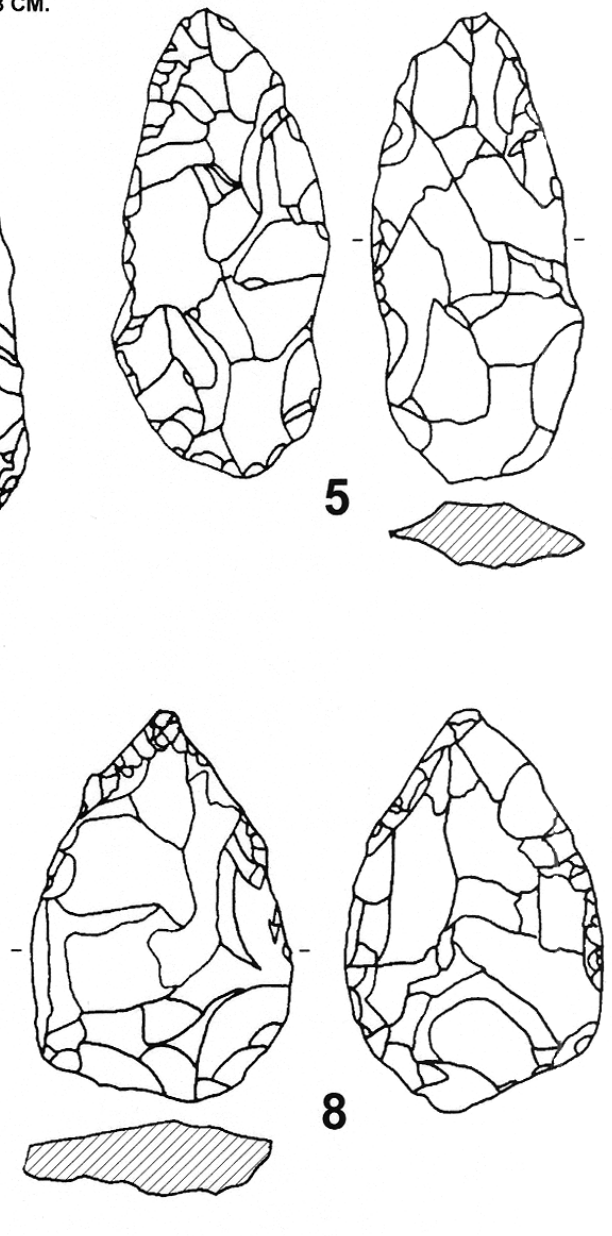

A Figura 10. Hojas de laurel no acabadas (HLna). 

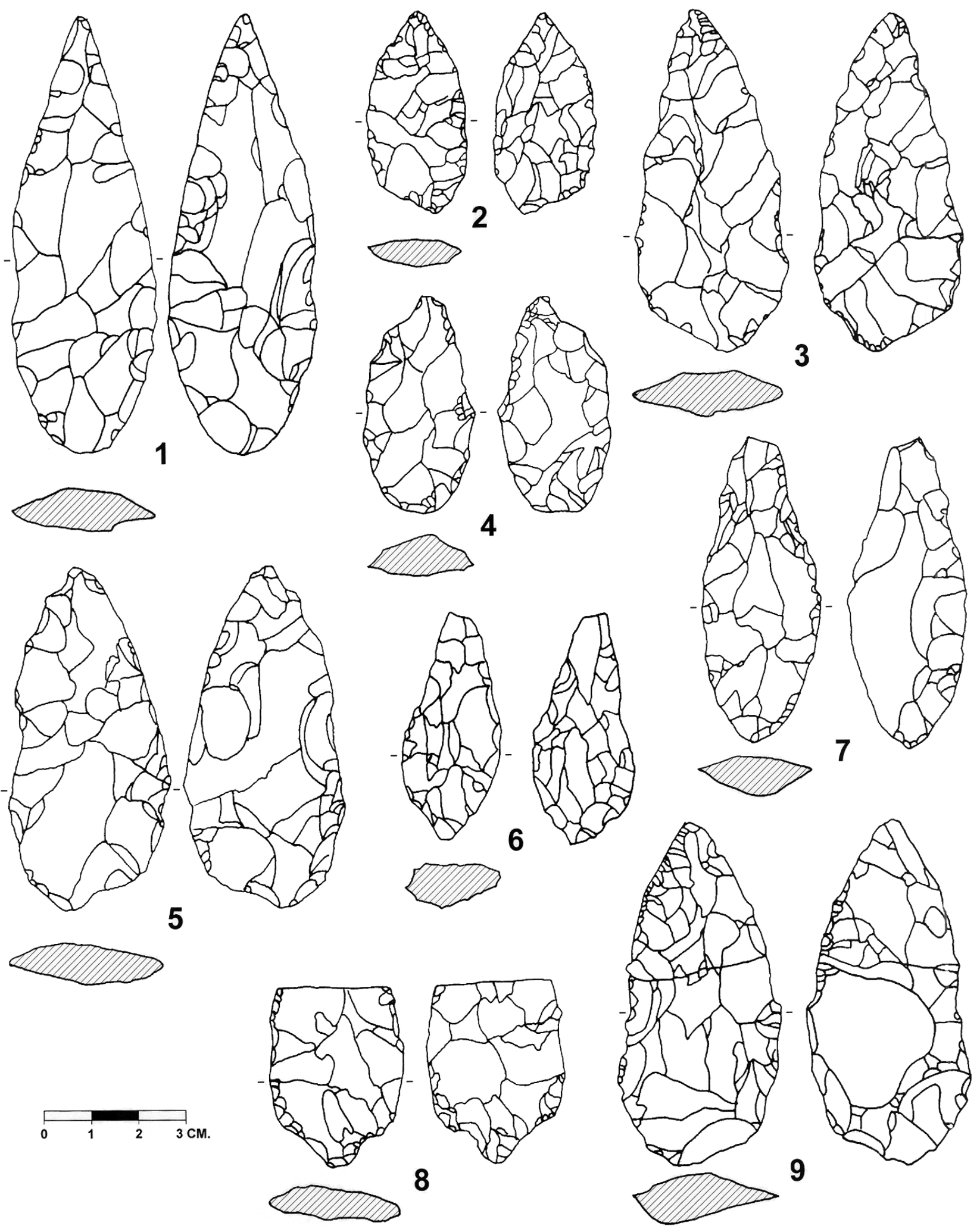

\ Figura 11. Hojas de laurel. 

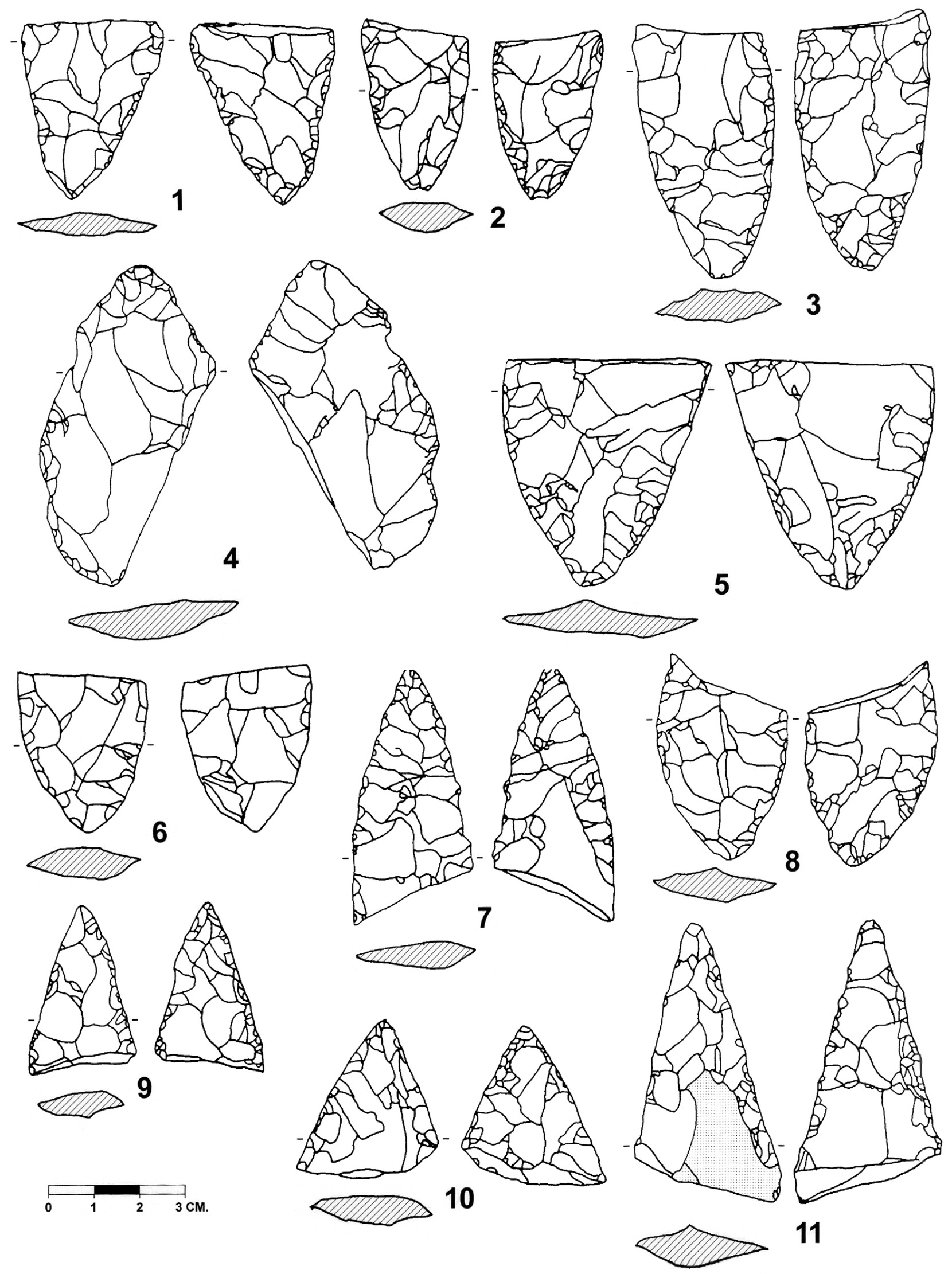

A Figura 12. Hojas de laurel. 
bada, las secciones transversales, lenticulares y simétricas aumentan considerablemente, sobre todo en la zona distal y mesial. Por lo tanto, el retoque consigue una aproximación morfológica casi definitiva al producto final.

Las HL se caracterizan por el empleo casi único del percutor blando, solo en el 2,19\% del anverso se produce lo contrario, (fig. 6 y figs. 11-12). Los retoques son planos $(98,54 \%)$ o simpleplanos $(1,46 \%)$ en el anverso y planos $(99,26 \%)$ o simples $(0,74 \%)$ en el reverso, (fig. 7). En las puntas acabadas las extracciones alcanzan su máxima amplitud con un $93,43 \%$ de retoques planos en anverso y $85,19 \%$ en reverso, seguidos de los profundos $(5,84 \%$ y $6,67 \%)$ y prácticamente los normales desaparecen (0,73\% y 0,74\%), (fig. 8).

A lo largo de todo el trabajo de reducción bifacial no hay una preocupación especial por conseguir retoques regulares, alargados y perpendiculares al eje de simetría. No obstante, la orientación de los retoques es fundamentalmente perpendicular por la dirección natural de trabajo a lo largo de los bordes de la pieza: $72,00 \%$ en anverso y $81,82 \%$ en reverso de las PSB; $65,63 \%$ y $78,13 \%$ en las HL.na y $78,10 \%$ y $82,96 \%$ en las HL. Los oblicuos aparecen para eliminar levantamientos embotados que no permiten seguir obteniendo extracciones de la amplitud deseada. Todos los levantamientos son más anchos que largos, salvo en las $\mathrm{HL}$, donde en un $5,84 \%$ de los anversos y en un $4,44 \%$ de los reversos las extracciones son alargadas, paralelas entre sí y regulares, lo que indicaría el empleo de la talla por presión para el acabado final de la pieza. Estos levantamientos se localizan fundamentalmente en el extre- mo distal y la base, es decir, las dos zonas con implicaciones funcionales de la pieza.

A lo largo de este trabajo hemos intentado a partir de datos objetivamente cuantificables realizar una primera aproximación al proceso de fabricación de las hojas de laurel del Solutrense Extracantábrico. Como hemos visto hay algunos parámetros comunes con las puntas ligeras de proyectil, sobre todo con las puntas de aletas y pedúnculo, con las que guardan bastantes similitudes tecnológicas. Sin embargo, en aquellos aspectos que determinan implicaciones funcionales y cinegéticas las divergencias son evidentes.

El paradigma que hasta ahora teníamos de este tipo de útil, caracterizado por un empleo importante del retoque por presión, con levantamientos alargados y paralelos entre sí mediante series organizadas, escaso grosor y una longitud importante, no parece adecuarse totalmente al Solutrense del mediterráneo, o al menos al yacimiento de estudio. Por lo tanto, el modelo tecnológico obtenido del área "clásica" para aquellos elementos tipológicos comunes a las dos regiones muestra algunas divergencias notables. No obstante, estas diferencias en la tipometría y morfología del producto final no deberian traducirse automáticamente en una mayor o menor eficacia cinegética, sin un estudio experimental que lo corrobore o desmienta. Deben tenerse en consideración otros aspectos igualmente determinantes como la adecuación a ecosistemas diferentes con presas potenciales también desiguales y tradiciones culturales distintas, asentadas durante el periodo de formación de este tecnocomplejo.

\section{BIBLIOGRAFÍA}

BAENA; J. (Ed.) (1998): Tecnología lítica experimental. Introducción a la talla del utillaje prehistórico. B.A.R.I.S., 721: 236 pp.

CallahAN, E. (1996) "The basics of biface knapping in the eastern fluted point tradition: a manual for flintknappers". Archaeology of Eastern North America, 7: 1-180. Reedición de 1979. Ontario.

Mallıo, J. M. (1999): "Esquemas operativos y conocimiento técnico: el caso del yacimiento solutrense de Vale Alominha (Torres Vedras, Portugal)". Espacio, Tiempo y Forma. Serie I, Prehistoria y Arqueología, 12: 185-214. Madrid.

Muñoz, F. J. (2000): Las puntas ligeras de proyectil del Solutrense Extracantábrico. Análisis tecnomorfológico e implicaciones funcionales. Aula Abierta. UNED, 357 pp. Madrid.

MuÑoz, F. J. y RIPOLL, S. (2001): "Las puntas de aletas y pedúnculo del Solutrense extracantábrico: Cadena operativa de fabricación." XXVII Congreso Nacional de Arqueología. 6-8 de mayo de 2003. Huesca. Boslkan, 18: 139-146. Huesca.

Pelegrin, J. (1981) "Experiments in bifacial work (about "laurel leaves)". Flintknaper's Exchange, 4 (1): 5-7.

Ripoll, E. (1960-61): "Excavaciones en Cueva de Ambrosio (Vélez Blanco, Almería). Campañas 1958 y 1960". Ampurias, XXII-XXIII: 3145. Barcelona.

- (1962): "Excavaciones en Cueva de Ambrosio (Vélez Blanco, Almería)". VII Congreso Nacional de Arqueología: 117-121. Barcelona. 1961".
RIPOLL, S. (1986): El Solutrense de La Cueva de Ambrosio (Vélez-Blanco, Almería): Campaña de 1963. Excavaciones Arqueológicas en España, 148: 205 pp. Madrid.

- (1988) El Solutrense de la Cueva de Ambrosio (Almería, Spain) y su posición cronoestratigráfica en el Mediterráneo Occidental. B.A.R.I.S., 462: 596 pp. (2 vols.).

RIPOLL, S. y CACHO, C. (1990): "Le Solutréen dans le Sud de la Péninsule lbérique". Les industries à pointes foliacées du Paléolithique Supérieur européen, (J. Kozlowski org.). Actes du Colloque de Cracovie, 1989. E.R.A.U.L., 42: 449-466.

Ripoll, S., Muñoz, F. J., Paniagua, J. P., Calleja, F. y Amaya, C. (1997): «La Cueva de Ambrosio (Almeria): nuevas aportaciones. El arte rupestre paleolítico". El món mediterrani després del Pleniglacial (1800012000 B.P.), (J. Ma Fullola y N. Soler eds.). Banyoles 18-20 mayo de 1995. Centre d'Investigations Arqueològiques. Serie Monogràfica, 17: 385-398. Girona.

Ripoll, S., PÉrez, S., López, J. R., Martos, J. A. y MuÑIz, M. (1997) "Las estructuras de combustión de la Cueva de Ambrosio. Estudio preliminar". El món mediterrani després del Pleniglacial (18000-12000 B. P.), (J. Ma Fullola y N. Soler eds.). Banyoles 18-20 mayo de 1995. Centre d'Investigations Arqueològiques. Serie Monogràfica, 17: 399-409. Girona.

Sмітн, Рн. (1966): Le Solutréen en France. Institut de Géologie du Quaternaire de Bordeaux. Impriméries Delmas. 450 pp. Bordeaux.

WHITTAKER, J. C. (1994): Flintknapping: making and understanding stone tools. University of Texas Press. 341 pp. 